\title{
Lésbicas na academia: \\ visibilidades relâmpago, transparente e palpável
}

\author{
MARTINS, Luisa Bitencourt ${ }^{1}$ \\ AUAD, Daniela $^{2}$
}

\section{RESUMO}

Com o objetivo de compreender a presença das lésbicas na produção acadêmica, este trabalho considera o conceito de heterossexualidade compulsória e leva em conta as interseccionalidades de gênero, raça e classe. Foi feita revisão bibliográfica em anais das últimas três edições de três eventos representativos: Reunião Nacional da ANPEd, Seminário Internacional Fazendo Gênero e Seminário Internacional Desfazendo Gênero. De um corpus com 145 artigos sobre ensino superior, gênero e feminismos, agrupados em 10 categorias, selecionamos a categoria Ações na Universidade para análise neste artigo, contendo16 trabalhos. A palavra lésbica e derivadas ou sinônimas desta foram buscadas e foram encontradas em 8 trabalhos: 3 mencionam lésbicas, 4 mencionam apenas sigla da diferença entre a população LGBT e apenas 1 discorre aprofundadamente sobre ser lésbica. A partir da análise, foi possível concluir que os textos não representam lésbicas, não trazem abordagens interseccionais e dão margem para uma visão homogênea da população LGBT.

Lésbicas. Ensino Superior. Feminismos. Relações de Gênero. Educação.

\section{Lesbians in academy: flashing, transparent and palpable visibilities}

\section{ABSTRACT}

In order to understand the presence of lesbians in academic production, this paper considers the concept of compulsory heterosexuality and takes into account the intersectionalities of gender, race and class. Bibliographic review was made in annals of the last three editions of three representative events: ANPEd National Meeting, International Seminar Making Gender and International Seminar Undoing Gender. From a corpus with 145 articles on higher education, gender and feminisms, grouped into 10 categories, we selected the University Actions category for analysis in this article, containing 16 papers. The word lesbian and its derivatives or synonyms were searched and found in 8 papers: 3 mention lesbians, 4 mention just marking the difference between the LGBT population and only 1 discusses deeply being a lesbian.

\footnotetext{
${ }^{1}$ Mestranda em Educação na UFJF. Licenciada em Letras na UFRGS. E-mail: bitencourtluisa@gmail.com. Lattes: http://lattes.cnpq.br/5869735454512235. ORCID: https://orcid.org/0000-0002-3648-6140.

2 Doutora em Educação. Professora da Pós-Graduação em Educação na UFJF. E-mail: auad.daniela@gmail.com. Lattes: http://lattes.cnpq.br/8903433226323112. ORCID: https://orcid.org/0000-0002-9805-1708.
}

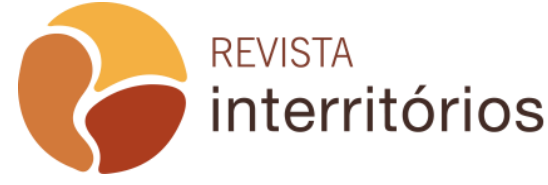

Interritórios | Revista de Educação Universidade Federal de Pernambuco, Caruaru, BRASIL | V.6 N.10 [2020] 
From the analysis, it was concluded that the papers do not represent lesbians, do not bring intersectional approaches, contributing for a homogeneous view of the LGBT population.

Lesbian. Higher Education. Feminisms. Gender Relations. Education.

\section{Lesbianas en la universidad: visibilidades efímeras, transparentes y palpables}

\section{RESUMEN}

Para comprender la presencia de lesbianas en la producción académica, este artículo considera el concepto de "heterosexualidad compulsoria" y tiene en cuenta la interseccionalidad de género, raza y clase. Se realizó una revisión bibliográfica en los anales de las últimas tres ediciones de tres eventos representativos: Reunión Nacional ANPEd, Seminario Internacional Making Gender y Seminario Internacional Undo Gender. De un corpus con 145 artículos sobre educación superior, género y feminismos, agrupados en 10 categorías, seleccionamos la categoría Acciones en la Universidad para su análisis en este artículo, que contiene 16 artículos. La palabra lesbiana y sus derivados o sinónimos se encontraron en 8 trabajos: 3 mencionan a las lesbianas, 4 mencionan solo la abreviatura de la diferencia entre la población LGBT y solo 1 discute profundamente sobre ser lesbiana. A partir del análisis, fue posible concluir que los textos no representan a las lesbianas, no brindan enfoques interseccionales y permiten una visión homogénea de la población LGBT.

Lesbianas. Enseñanza superior. Feminismos. Relaciones de Género. Educación.

\section{Lesbiche all'università: visioni effimere, trasparenti e palpabili}

\section{SINTESE}

Per comprendere la presenza di lesbiche nella produzione accademica, questo articolo prende in considerazione il concetto di "eterosessualità obbligatoria" e tiene conto dell'intersezionalità di genere, razza e classe. Una revisione bibliografica è stata effettuata negli annali delle ultime tre edizioni di tre eventi rappresentativi: ANPEd National Meeting, International Making Gender Seminar e Undo Gender International Seminar. Da un corpus con 145 articoli su istruzione superiore, genere e femminismo, raggruppati in 10 categorie, selezioniamo la categoria Azioni dell'Università per l'analisi in questo articolo, che contiene 16 articoli. La parola lesbica e i suoi derivati o sinonimi sono stati trovati in 8 articoli: 3 menzionano lesbiche, 4 menzionano solo l'abbreviazione della differenza tra la popolazione LGBT e solo 1 discute profondamente sull'essere lesbica. Dall'analisi, è stato possibile concludere che i testi non 
rappresentano le lesbiche, non forniscono approcci intersezionali e consentono una visione omogenea della popolazione LGBT.

Lesbiche. Istruzione Superiore. Femminismi. Relazioni di genere. Istruzione.

\section{INTRODUÇÃO}

Nas últimas décadas, a produção acadêmica passou a abordar, de diversos modos, assuntos da população LGBT (lésbicas, gays, bissexuais e pessoas trans ${ }^{3}$ ) no Brasil. No entanto, ainda são escassos tanto dados sobre a realidade social desta população quanto produção acadêmica que analise suas especificidades. Nesse cenário, para pensar as condições sociais da vida das mulheres lésbicas no Brasil, destacamos, dentre as informações disponíveis para acesso, duas delas: os dados divulgados pelo Grupo Gay da Bahia (GGB), no documento intitulado Mortes violentas de LGBT+ no Brasil: Relatório 2018, e o Projeto de Pesquisa Lesbocídio (2018), realizado pelas pesquisadoras Milena Cristina Carneiro Peres, Suane Felippe Soares e Maria Clara Dias. O documento do GGB aponta a morte de 420 LGBTs, de modo violento, no ano referido (GGB, [2019]). Já, no segundo documento citado, resultante de pesquisa realizada entre janeiro e setembro de 2018, no Brasil, foram encontradas 117 mortes de mulheres lésbicas, sendo, nestes casos, determinante para a ocorrência dos óbitos o fato pessoa morta ser lésbica. Ambas as publicações assinalam dificuldades em encontrar informações e, em razão disso, afirmam haver subnotificação dos dados. Exemplar dessa dificuldade quanto aos dados são as colocações do Dossiê Assassinatos e violências contra travestis e transexuais no Brasil em 2018. Tal documento foi elaborado pela Associação Nacional de Travestis e Transexuais do Brasil (ANTRA) e reforça que a falta de dados sobre a população trans nos relatórios sobre LGBTs motivou a própria organização na realização de levantamento de dados (BENEVIDES; NOGUEIRA, 2019).

Peres, Soares e Dias (2018), ao encontrarem estatísticas antes desconhecidas sobre lésbicas, também reforçam o descaso do Estado em conhecer estes dados. Além disto, as pesquisadoras afirmam que tudo indica que a subnotificação seja mais expressiva em relação a mulheres negras, amarelas e indígenas, sendo estas últimas as com menos registro das violências que interpelam suas vidas. Esta falta de dados se mostra preocupante, visto que invisibiliza a realidade social destas populações e dificulta o enfrentamento às desigualdades sociais por parte das esferas

\footnotetext{
3 Utilizamos "pessoas trans" por razão de que este é o termo que tem sido mais comumente empregado no movimento social, costumando funcionar como um guarda-chuva que engloba mulheres transexuais, homens transexuais, travestis, pessoas não-binárias, entre outros. 
governamentais, que deveriam ser assumidas como um desafio às políticas públicas em todas as searas.

Em relação às pesquisas acadêmicas, o aumento de estudos sobre gênero, desde os anos 1980 (AUAD, 2004), junto à inserção de mulheres em universidades, vêm aprofundando os estudos sobre o tema e colaborando para a ampliação das lutas dos movimentos sociais de mulheres e LGBTs, no Brasil. Sobre as mudanças encontradas no ambiente acadêmico acerca deste assunto, a pesquisadora Fúlvia Rosemberg (2001) analisa dados que demonstram a rápida expansão do número de matrículas de mulheres em ambientes formais de educação, no Brasil, desde os anos 1970. Por outro lado, Rosemberg (2001) aponta que estes números isolados não garantem equidade no ambiente de ensino, principalmente pelo agrupamento dos números não considerar questões de raça e classe na discriminação dos dados, bem como não considerar outras questões de acesso e permanência, como em quais as áreas de conhecimento estão estas mulheres ou condições de maternidade. A respeito disso, a pesquisadora traz dados que demonstram o aumento da presença de mulheres em alguns cursos que costumavam ser relacionados a profissões masculinas, como direito e administração, mas demonstra que mulheres ainda são pouco frequentes na maioria dos outros cursos, reforçando que ainda há separações entre homens e mulheres nos ambientes de ensino no Brasil. Desta forma, observar apenas o crescimento do número de matrículas de mulheres no ensino superior pode ocultar desigualdades acadêmicas, principalmente, como aponta Rosemberg (2001), pela falta de dados que possam nos dar informações mais completas sobre estas realidades, sobretudo no que diz respeito às condições de permanência e trajetórias acadêmicas.

Neste cenário, ressaltamos a implementação de políticas de ação afirmativa, especialmente as cotas raciais, promulgadas pela lei $n$ ํㅜ 12.711 de 2012, que agem no intuito de expandir o acesso de pessoas de classes populares e de pessoas negras ou pardas. As autoras Daniela Auad e Ana Luisa Cordeiro (2018) lembram que as políticas de ação afirmativa estão em consonância com as indicações do Relatório de Durban (2001), o qual o Brasil assinou, e que suas conquistas são fruto de movimentos sociais que historicamente lutam por elas:

No contexto nacional, acompanhou-se uma série de pressões sociais vindas de grande parte do movimento negro e do movimento de mulheres negras para que as desigualdades históricas fossem enfrentadas por meio de ações preventivas, reparadoras, compensatórias e de curto prazo, especialmente as cotas (AUAD; CORDEIRO, 2018, p. 196).

Isto posto, neste artigo nos propomos a colaborar para a discussão sobre permanência universitária de lésbicas, que estão integradas à população e aos 
movimentos de mulheres e de LGBTs, bem como são parte da população negra, indígena e outras tantas que historicamente vem sendo marginalizadas socialmente no Brasil. Desta forma, consideramos os dados das condições sociais e acadêmicas apresentados acima como parte do cenário em que as lésbicas adentram as universidades, e, a partir disso, analisamos a presença das lésbicas em um determinado conjunto de pesquisas em que a categoria gênero tenha sido adotada e que se debrucem sobre o ensino superior.

\section{Visibilidade Lésbica e questões de interseccionalidade}

No bojo da pesquisa e dentre as abordagens adotadas, elegemos o conceito de heterossexualidade compulsória, difundido por Adrienne Rich, em 1980, mas publicado no Brasil apenas em 2010, no artigo intitulado Heterossexualidade compulsória e a existência lésbica.

Rich entende que a heterossexualidade é imposta às mulheres como forma de garantir o poder dos homens sobre elas. Desta forma, a autora afirma que a violência e crueldade nas relações heterossexuais - como a exploração do trabalho doméstico e o estupro dentro do casamento, por exemplo - são comumente vistas como normais, enquanto as relações entre mulheres são colocadas como estranhas e doentias. Sendo assim, a heterossexualidade compulsória reitera às mulheres que elas são ou deveriam ser heterossexuais e, por conseguinte, ter em seu cotidiano, de forma naturalizada, a sua exploração social e mental, em favor dos homens e do capitalismo. Essa conjuntura seria a responsável primeira pela invisibilidade e interdição da possibilidade das mulheres se perceberem como e serem lésbicas. Por conta disto, Rich defende que, embora a homossexualidade feminina e a homossexualidade masculina sejam ambas sexualidades consideradas dissidentes, há diferenças entre elas. Às mulheres restaria um conjunto de desigualdades, pelo fato de serem mulheres, diferente do que ocorre com os homens homossexuais. Assim, consequentemente, a autora - com o que concordamos - entende que tratar as sexualidades masculina e feminina como iguais é o equivalente a apagar a existência lésbica. Vale notar que essa conclusão da autora se desdobra, portanto, ao se pensar nas inúmeras vezes em que mulheres lésbicas são citadas como se pudessem ser "englobadas" nas necessidades de toda a população gay, como se essas necessidades fossem representadas pelo o que homens, brancos e cisgêneros determinam, uma vez que estes muitas vezes são dominantes tanto nos movimentos sociais quanto na academia.

Adrianne Rich também pondera que a heterossexualidade oculta as tradições femininas e as próprias mulheres da história, ao valorar como mais prestigiosas, e de forma acentuada, as buscas e intenções masculinas 
culturalmente. Em razão disto, a autora reforça que é preciso romper a invisibilidade imposta às mulheres - especialmente às lésbicas -, visto que não tornar visível a possibilidade da lesbianidade para as mulheres é uma das formas de manter os privilégios masculinos através da perpetuação da heterossexualidade como única sexualidade existente. Em consonância com Adrienne Rich, nos propomos neste trabalho a pensar o acesso e permanência universitária de lésbicas, buscando compreender como - e se - as lésbicas estão presentes nas produções acadêmicas, especificamente dentro do campo sobre educação, no qual relações de gênero e feminismos podem motivar potentes análises e transformações.

Além disto, Rich menciona que os diferentes pertencimentos sociais criam especificidades para as violências sofridas por mulheres e, por isso, estas violências nem sempre ocorrem de igual forma. Outras autoras se debruçam sobre esta questão de forma mais aprofundada, como Audre Lorde (s/d), em Não há hierarquia de opressão. Lorde enfatiza que não é possível hierarquizar ou separar as diferentes opressões vividas pelas mulheres pois, conforme a autora, uma mulher lésbica negra e periférica sempre levará consigo, simultaneamente, particularidades referentes às opressões de gênero, raça e classe social que são impostas a ela. Assim, a poeta Lorde sustenta que é preciso lutar contra todas as opressões a grupos discriminados, reconhecendo as particularidades de cada um para somar as lutas e não para separá-los. É nesta perspectiva que apoiamos nossas análises, posto que entendemos que as lésbicas, ainda que um grupo heterogêneo, possuem particularidades próprias, gerando desigualdades sociais com origem e consequências específicas e que não se igualam sempre, por exemplo, aos homens homossexuais, estes também sendo um grupo com diferenças internas. O que assinalamos aqui é algo que as pesquisadoras Daniela Auad e Cláudia Lahni apontam e analisam em profundidade, em seu artigo intitulado Cidadania Democrática e homossexualidades: comunicação no combate à violência contra as mulheres lésbicas:

Às mulheres lésbicas recai a diferença hierarquizada do feminino (sempre em relação ao masculino como padrão hegemônico) e, soma-se a isso, a desigualdade relativa à homossexualidade. Duplamente desviantes, porque não homem e não heterossexual, as mulheres lésbicas sofrem, na maior parte do tempo, dupla discriminação, específicas desigualdades e muita invisibilidade no que se refere aos aspectos que definem sua identidade sexual e de gênero. Nesse sentido, os processos de identificação e as políticas de reconhecimento são uma necessidade e urge a construção de múltiplos modelos. Quanto mais opções disponíveis, mais possibilidades para exercício da sexualidade. E esse múltiplo leque também pode ser percebido como outra faceta da diversidade abordada no presente texto e comumente 
associada ao termo, tanto no meio acadêmico quanto no senso comum. Trata-se da existência de um número tal de modelos e padrões tanto quanto fosse a quantidade de tipos de pessoas que podem existir, onde quer que estejam e da maneira como desejarem ser. Trata-se de ter como modelo o não-modelo. Ou, o que pode ser percebido como utopia, trata-se de não ter modelo. Por mais inatingível que pareça essa demanda, sua enunciação pode ampliar as possibilidades de visibilidade das múltiplas sexualidades e concorrer para 0 alcance $e$ reconhecimento de direitos fundamentais. (AUAD; LAHNI, 2013, p.157).

Também na direção de analisar as diferenças em cenários de desigualdades, Cheryl Clarke no artigo El lesbianismo: Un Acto de Resistencia (1988) tece considerações sobre as relações entre raça, classe e gênero. A autora analisa a resistência de mulheres lésbicas negras nos Estados Unidos e sustenta que, se as vivências dos homens negros são interpeladas pelo racismo e a das mulheres brancas pelo sexismo homofóbico, as vivências de lésbicas negras serão interpeladas, concomitantemente, pelas duas formas de opressão que geram desigualdades sociais. Assim, Clarke compreende que há distanciamentos e aproximações entre estes grupos, de forma que a heterossexualidade impele a todas as mulheres à servidão. Entretanto, isto ocorre de modo diferente quando se consideram outras opressões vivenciadas conjuntamente, como as de raça e classe. Em vista disso, Clarke aposta em um feminismo lesbiano que seja ao mesmo tempo antirracista e anticlassista, no qual a visibilidade lésbica é potente estratégia para mudanças que levem à libertação das mulheres.

No que tange às lésbicas universitárias, o trabalho de Daniela Auad e Ana Luisa Cordeiro (2018), intitulado $A$ interseccionalidade nas políticas de ação afirmativa como medida de democratização da educação superior, contribui para este debate, ao realizar análise das desigualdades sociais presentes no acesso e permanência de estudantes lésbicas e bissexuais negras cotistas. As autoras debatem as diversas violências vividas por mulheres negras, especialmente na educação e no mercado de trabalho, e discutem a presença das mulheres cotistas negras lésbicas e bissexuais no ambiente universitário. Tal ambiente institucional se reafirmaria continuamente como não sendo o lugar das mulheres cotistas negras lésbicas e bissexuais, como se fossem enviadas permanentemente mensagens verbais e não verbais sobre esse não ser o lugar delas. Apesar disso, as autoras sugerem que a presença das mulheres cotistas negras lésbicas e bissexuais na universidade tem potencial de desestabilizar a ordem e as hierarquias naturalizadas:

Essas mulheres adentram a universidade, um espaço culturalmente elitizado, com uma produção de conhecimento pautada pelos e nos homens, brancos, heterossexuais, 
cristãos, de classe média alta, adultos, do meio urbano e sem qualquer marca que os coloquem na condição de pessoa com deficiência. Muito distantes desse padrão considerado de excelência 'de saída', a trajetória acadêmica das mulheres negras que o presente artigo focaliza é uma constante resistência ao que está posto hegemonicamente, estremecendo essa ordem compulsória racista e heteronormativa (AUAD; CORDEIRO, 2018, p. 201).

Diante disto, e em consonância com as autoras citadas acima, realizamos análise da presença de lésbicas na produção acadêmica, visto que entendemos como necessário romper a invisibilidade lésbica na academia para desestabilizar pressupostos que sustentam as injustiças acadêmicas contra as mulheres, em especial as lésbicas. Conforme explorado, é ainda parte do nosso empenho de pesquisa compreender como que, dentre as mulheres lésbicas, diferentes condições sociais influenciarão nas suas trajetórias de vida acadêmica, a partir de raça, classe e gênero, bem como outras condições que podem se mostrar relevantes a depender do contexto social das lésbicas.

\section{O Corpus de Análise}

Segundo os caminhos de pesquisa traçados, foi realizada revisão bibliográfica de anais das últimas três edições de três eventos de relevância nacional: Reunião Nacional da ANPEd (Associação Nacional de PósGraduação e Pesquisa em Educação), Seminário Internacional Fazendo Gênero e Seminário Internacional Desfazendo Gênero4. Dos 7043 trabalhos disponíveis, buscamos aqueles que abordavam ensino superior ao mesmo tempo em que gênero e feminismos foram considerados na análise. A seleção foi feita através da leitura dos títulos de todos os artigos e acessando os resumos, nos casos em que os títulos não eram elucidativos. Desta forma, encontramos 145 trabalhos que se enquadraram nos critérios de seleção, cuja distribuição em cada edição dos eventos pode ser observada abaixo, no Quadro 1:

Quadro 1: Número de trabalhos selecionados na pesquisa, segundo edição do evento, Brasil, 2019

\begin{tabular}{|l|r|l|r|r|}
\hline \multicolumn{1}{|c|}{ Evento } & Ano & \multicolumn{1}{|c|}{ Local } & \multicolumn{1}{c|}{$\begin{array}{c}\text { Artigos } \\
\text { Selecionados }\end{array}$} & $\begin{array}{c}\text { Total de } \\
\text { Artigos }\end{array}$ \\
\hline ANPEd 36 & 2017 & Goiânia - GO & 3 & 327 \\
\hline ANPED 37 & 2015 & Florianópolis- SC & 3 & 512 \\
\hline
\end{tabular}

4 Trabalhos disponíveis nos sites dos eventos, respectivamente: http://www.anped.org.br/reunioes-cientificas/nacional, http://www.fazendogenero.eventos.dype.com.br/ e http://desfazendogenero.com.br/. 
Lésbicas na academia: visibilidades relâmpago, transparente e palpável

\begin{tabular}{|l|r|l|r|r|}
\hline ANPED 38 & 2013 & São Luís - MA & 4 & 520 \\
\hline Fazendo Gênero 9 & 2010 & Florianópolis - SC & 18 & 1125 \\
\hline Fazendo Gênero 10 & 2013 & Florianópolis - SC & 21 & 1304 \\
\hline $\begin{array}{l}\text { MM \& Fazendo Gênero } \\
11\end{array}$ & 2017 & Florianópolis - SC & 57 & 1833 \\
\hline I Desfazendo Gênero & 2013 & Natal - RN & 6 & 208 \\
\hline II Desfazendo Gênero & 2015 & Salvador - BA & 17 & 759 \\
\hline III Desfazendo Gênero & 2017 & $\begin{array}{l}\text { Campina Grande - } \\
\text { PA }\end{array}$ & 16 & 455 \\
\hline TOTAL & & & $\mathbf{1 4 5}$ & $\mathbf{7 0 4 3}$ \\
\hline
\end{tabular}

Fonte: Elaborado pelas autoras

Em seguida, durante a leitura dos resumos, foram feitas anotações sobre o conteúdo dos trabalhos, principalmente em relação aos temas abordados, conferindo o corpo do texto, através de leitura dinâmica e transversal sempre que se mostrou necessário. Em razão de aspectos de proximidade que nos chamaram a atenção, optamos por agrupar artigos que apresentavam assuntos em comum, gerando a criação de 10 categorias, que podem ser visualizadas abaixo, no Quadro 2:

Quadro 2: Categorias de análise criadas a partir dos artig
\begin{tabular}{|ll|}
\hline 1. & Acesso e permanência na universidade \\
\hline 2. & Ações na Universidade \\
\hline 3. & Currículo \\
\hline 4. & Estudos sobre Políticas Públicas \\
\hline 5. & Percepções sobre gênero \\
\hline 6. & Produção Acadêmica \\
\hline 7. & Programas Mulheres nas Ciências \\
\hline 8. & Quadro de docentes \\
\hline 9. & Trajetórias Discentes \\
\hline 10. & Trajetórias Docentes \\
\hline
\end{tabular}

Fonte: Elaborado pelas autoras

A criação destas categorias revela escolhas feitas por nós e estão atreladas às marcas das nossas trajetórias enquanto pesquisadoras. Dessa forma, associamos os trabalhos, e assim os agrupamos, por entendermos que eles revelam aproximações em seus temas de análise sem, contudo, ignorar suas diferenças no tocante a suas abordagens, metodologias e aportes 
teóricos. Não se pretende aqui afirmar uma unidade entre os trabalhos, mas sim agrupar aqueles cujas discussões percebemos estar mais próximas em suas temáticas.

Buscamos, no corpo dos textos selecionados, a presença de palavras relacionadas a homossexualidade e/ou lésbicas, a fim de iniciar o entendimento sobre como - e se - apareciam lésbicas no corpus de análise. Para o presente artigo, dos 145 trabalhos encontrados, conforme os critérios explicitados acima, colocamos sob análise 16 trabalhos, os quais compõe a categoria Ações na Universidade. Dentro desta categoria, foram encontrados 8 textos com a palavra lésbica ou palavras derivadas (como lesbianidade, lésbico, lesbofobia, entre outras). Deste modo, analisaremos como se dá a discussão sobre lésbicas nestas 8 produções.

\section{Como as Lésbicas aparecem nas Produções Acadêmicas}

A categoria Ações na Universidade apresenta trabalhos que versam sobre ações desenvolvidas no interior da universidade e são, em sua maioria, vinculadas a projetos de extensão em que a categoria gênero estava presente. Dos 16 trabalhos selecionados, 8 apresentaram 3 formas de visibilidade, as quais passaremos a descrever analiticamente, tendo sido por nós nomeadas a partir de três metáforas. Estas fazem referência a como o olhar de parte da sociedade pode ser direcionado às lésbicas: a visibilidade relâmpago, a visibilidade transparente; e a visibilidade palpável.

A visibilidade relâmpago foi assim nomeada pois se refere a 3 trabalhos que mencionam as lésbicas de forma rápida e passageira, com menção de curtíssima duração, tal como a brevidade de um relâmpago, que pode iluminar, mas sequer faz barulho de fato, como no caso de um trovão.

A visibilidade transparente, com 4 trabalhos que falam de lésbicas descrevendo-as como parte da sigla LGBT, mas sem maiores considerações, como se o sentido da lesbianidade ali estivesse, mas de modo oculto, atenuado e que, mesmo deixando a luz passar e se tornando visível, ainda não permite que se distinga quais especificidades estão por trás da letra $L$ - de lésbicas da sigla LGBT.

$\mathrm{E}$, enfim, a visibilidade palpável, com apenas 1 artigo que apresenta lésbicas considerando especificidades desta população, sem deixar dúvidas sobre o sentido das palavras, posto que no texto em questão podemos ver com nitidez as lésbicas que são tema do estudo. A seguir, nos subtítulos, as metáforas serão melhor delineadas e analisaremos os trabalhos, de modo a demarcar como aparecem a palavra lésbica, seus sinônimos e palavras derivadas. 


\section{Visibilidade Relâmpago}

O relâmpago é uma luz de curta duração que, geralmente, aparece entre uma nuvem e outra. Utilizamos aqui a metáfora do relâmpago para descrever 3 trabalhos em que lésbicas e palavras derivadas ou sinônimas são mencionadas de forma rápida, como uma luz que se lança e em um piscar de olhos se dissolve: é possível vê-los, mas logo se vão, sem sequer serem ouvidos como um trovão. Assim, os 3 trabalhos desta seção visibilizam lésbicas como o relâmpago: curtos, sem alarde, mas existentes. Descreveremos como se dá essa visibilidade a seguir.

Faremos apenas rápidas considerações sobre os dois primeiros artigos, visto que não há grande discussão sobre o que pretendemos analisar. Publicado no Desfazendo Gênero III, em 2017, com autoria de María del Carmen Acuña-Rodríguez, Habitar (em) a burbuja universitária: a Universidad de Costa Rica é um trabalho que entende a universidade como potencial espaço de proteção para a população LGBTI ${ }^{5}$. Segundo a autora, na Universidade da Costa Rica a luta de pessoas dentro da universidade vêm conseguindo consolidar iniciativas de reconhecimento e afirmação (denominadas de IRA pela autora), exploradas por ela ao longo do texto. A título de exemplo, citamos algumas destas iniciativas discutidas pela autora: a realização de um evento acadêmico LGBTI, a criação de disciplinas que discutem gênero e a resolução interna da universidade sobre o uso de nome social para pessoas trans - estas, inclusive, somente citadas em referência ao direito do uso do nome social. Neste artigo, a única palavra relacionada à lésbica é lesbofobia, em um trecho ao mencionar o dia "17 de maio como Dia Nacional contra a homofobia, lesbofobia e transfobia" (ACUÑA-RODRIGUEZ, 2017, p. 1389).

Sobre raça, é feita uma única consideração quando se menciona o apagamento de diversidade étnica e cultural do país na região que se encontra a universidade, que constrói "a imagem das pessoas costarriquenhas como gente branca, do Vale Central, de classe média, católicas e pacíficas" (ACUÑARODRIGUEZ, 2017, p. 1387). No restante do trabalho, não são citadas nem feitas outras considerações sobre raça, classe ou qualquer outro aspecto.

Na mesma direção, segue o artigo de Eloisa Slongo e Emylli Nascimento, que publicaram Assessoria jurídica universitária popular: o relatório de assassinatos LGBT e os crimes de ódio na Paraíba, em 2015, no Desfazendo Gênero II. Este trabalho versa sobre um projeto de assessoria jurídica popular vinculado à universidade, sendo abordado, neste trabalho, especificamente 0 relatório de mortes LGBTs na Paraíba. As autoras retomam o histórico no país, no tocante a projetos de assessoria jurídica, com forte crescimento no momento

${ }^{5}$ Utilizamos aqui LGBTI por ser o termo usado pela autora do referido artigo. 
de ditadura militar do Brasil. O texto é desenvolvido na direção de descrever as ações do grupo do Núcleo de Extensão Popular Flor de Mandacaru (NEP). As pesquisadoras se voltam, particularmente, para a descrição da ação desenvolvida para levantamento de dados sobre a morte da população LGBT, na qual que gênero é um determinante para a ocorrência dos óbitos. A palavra lésbica surge, aparentemente, quase por acaso, ao se relatar a união entre parte dos movimentos sociais e o NEP, no âmbito do projeto denominado Grupo de Mulheres Lésbicas e Bissexuais da Paraíba Maria Quitéria.

Ao decorrer do artigo, não é feita nenhuma menção a aspectos identitários de raça, classe, geração, entre outros. A população LGBT aparece da primeira e última menção representadas por essas quatro letras, em que não se explicita nem que letras formam esta sigla e nem quem faz parte da população atendida pelo núcleo. Além disto, não se menciona em nenhum momento as vulnerabilidades que atingem de modo diferente as bissexuais, lésbicas, trans ou gays e, consequentemente, podem ser influenciadoras das mortes. As autoras são assertivas em afirmar a necessidade da distinção de crimes de ódio contra a população LGBT, visto que estes têm motivação específica, entretanto, não encontramos discussões sobre a heterogeneidade da população LGBT entre si.

Em que pese que o foco dos dois artigos mencionados são iniciativas para a população LGBT no geral, destacando sua unidade como grupo, e considerando que o espaço para artigos de anais de evento não é extenso, ainda assim acreditamos que seja possível e necessário explicitar que são diferentes os aspectos sociais de exclusão e desigualdades sociais vivenciados pelos diferentes sujeitos, sejam lésbicas, gays, bissexuais, trans ou intersexuais.

Se a população LGBT se institui, não sem razão, de uma população que carrega características em comum por serem parte do que se considera "dissidentes de gênero ou de sexualidade", também não é possível esquecer que não é uma população homogênea e uníssona. Não fazer sequer uma menção a isto, mesmo que brevemente, age na direção do apagamento das diferenças destes sujeitos, diferenças essas que levam a morte, segundo o próprio texto postula. Nele, se transparece uma falsa noção de equidade no interior da população LGBT, reforçando um tom "genérico" que acirra a invisibilidade das existências e homogeneíza as diferentes lutas por sobrevivência e por direitos, como das lésbicas e das mulheres transexuais, frequentemente invisibilizadas.

O terceiro artigo contabilizado como de visibilidade relâmpago foi publicado no Desfazendo Gênero III, em 2017. Ele também menciona a palavra lésbica brevemente e se intitula Uso e elaboração de material didático no PIBIDFrancês - UFRJ: abordando raça, gênero e sexualidades, de Sergio Luiz da 
Silva. Neste trabalho, o autor promete discorrer sobre a elaboração de materiais didáticos desenvolvida no projeto que analisa, ao dialogar sobre a formação docente dos bolsistas graduandos. Assim, o autor conta quem integra o PIBID em questão, descrevendo brevemente raça, gênero, sexualidade e religião de cada um. Neste momento, a palavra lésbica é encontrada, visto que uma das bolsistas é lésbica. Além disto, destacamos um relato mencionado nesta parte: o autor conta que a discussão sobre raça causou reflexão e mudança na auto declaração de uma aluna, que passou a se enxergar como negra, e de um aluno, que passou a se enxergar como indígena. Após este relato, não são feitas outras considerações sobre estes ou outros aspectos identitários dos integrantes do projeto e tão pouco a palavra lésbica ou derivadas são encontradas no restante do artigo.

Diferentemente dos dois artigos anteriores, neste encontramos a marcação de uma pluralidade de aspectos identitários, principalmente de raça, já indicada desde o título. Apesar desse mérito, contudo, a análise não vai muito além da sua descrição. $O$ pesquisador afirma que o projeto tem o intuito de abordar diferenças identitárias de gênero, raça e sexualidade. Por esta razão, o desenvolvimento do material procura "expor sujeitos diversos: negros, brancos, pobres, ricos, heterossexuais, homossexuais, transexuais, gordos, magros, cristãos, mulçumanos etc, pessoas que nem sempre (ou quase nunca) aparecem nos materiais didáticos de língua estrangeira" (SILVA, 2017, p. 2850). De acordo com o artigo, foram inseridos diversos personagens no material didático do projeto PIBID Francês, tais quais: uma mulher negra, seu primo gay casado e com filho e uma aluna gorda. Após elaborar este material, o autor conta que o grupo refletiu sobre estes personagens, mas ainda mantiveram um discurso hegemônico sobre sexualidade, classe e raça. $O$ autor espera que a reflexão que ele indica possa contribuir para alterar os próximos materiais.

Desta forma, faz-se notar que o projeto descrito pelo autor do trabalho é majoritariamente formado por relatos, de modo que aparentemente não sobra espaço para discussões aprofundadas sobre os aspectos identitários. Além disto, há dois movimentos nas descrições do artigo. Por um lado, são feitas breves menções, no início e no final do trabalho, que criticam modelos hegemônicos, o que inclui a heteronormatividade, a branquitude, os padrões de beleza e o que ele denomina como "mundo burguês comportado". Por outro lado, quando dos relatos da experiência do PIBID, é a pluralidade e riqueza de todas as diferenças que são valorizadas. Assim, há um esforço em fazer considerações sobre aspectos identitários e suas intersecções, mas elas são feitas de forma bastante descuidada, com pouco aprofundamento e descrições simplificadas, no interior do texto. Isso se mostra quando se mencionam os aspectos identitários e como eles afetam a formação dos/das bolsistas graduandos, salvo a questão de auto declaração de dois deles, que é rapidamente mencionada. $\mathrm{O}$ pouco aprofundamento e aligeiramento podem 
ainda ser percebidos na ausência de relato sobre como os materiais são recebidos pelos/as estudantes, sobre o que o único trecho encontrado se refere a uma proposta de aula: "aparentemente foi bem aceita pelo grupo" (SILVA, 2017, p. 2851). São ainda ausentes no artigo as discussões geradas a partir do material, posto que nenhum relato de sala de aula é apresentado, assim como inexistem outras reflexões sobre como este material pode impactar a realidade da comunidade acadêmica e escolar. $\mathrm{O}$ único aspecto apresentado sobre um possível impacto é a autocrítica sobre a necessidade de mudar os discursos hegemônicos, mesmo quando abordam homossexualidade.

\section{Visibilidade Transparente}

Os artigos denominados como visibilidade transparente totalizam 4 trabalhos, dentre os 08 artigos da categoria Ações na Universidade. São produções que falam de lésbicas descrevendo-as como parte da sigla LGBT, mas sem maiores considerações, como se o sentido da lesbianidade ali estivesse, mas de modo oculto, atenuado e que, mesmo deixando a luz passar e se tornando visível, ainda não permitisse que se distinga quais especificidades estão por trás da letra $L$ - de lésbicas - da sigla LGBT.

Assim, são quatro trabalhos em que utilizamos a metáfora da visibilidade transparente para explicar sua presença: as lésbicas estão visíveis, mas transparentes, sem conteúdo significativo ou transbordante. No decorrer dos artigos, lésbicas existem e têm forma, mas é como se alguém tivesse apagado seu preenchimento e sobrassem só silhuetas delineadas pela letra $L$, desde que esta esteja no interior da sigla LGBT, para poder existir desde que componha essa população. É possível vê-las, mas seu aspecto translúcido quase dissolve a sua forma em mistura a outras. As lésbicas estão ali, mas se não olharmos com atenção nosso olhar se dissipa, não se fixa e se vê através delas, de modo que se pode ter a impressão que elas não têm especificidades em relação aos gays, bissexuais e pessoas trans. A seguir, analisamos os artigos e explicamos como se dá essa visibilidade transparente em cada um deles.

Dos quatro artigos, dois abordam a população trans ${ }^{6}$ e foram publicados no Desfazendo Gênero II, em 2015. Um deles, intitulado Espaços potentes: a extensão universitária como possibilidade de fortalecimento da ação profissional no campo interventivo, de Márcia Santos, Guilherme Almeida e Andressa Abreu. $O$ artigo descreve a atuação de um projeto de extensão universitário do curso de Serviço Social em parceria com uma unidade de atenção especializada do hospital universitário Pedro Ernesto/UERJ, no processo transexualizador. $\mathrm{O}$ artigo discute o contexto de criação do projeto e

\footnotetext{
${ }^{6}$ Sobre estes artigos, nos limitamos a tecer considerações breves, visto que as menções à palavra lésbica, seus sinônimos e suas derivações são pontuais. 
centra suas discussões, em razão de seu foco, na população trans. Sendo assim, a palavra lésbica aparece duas vezes, ao descrever a sigla LGBT. Para além disto, sobre a categoria classe social, os autores consideram que o/a assistente social "não pode silenciar diante das complexas e contraditórias relações entre classe, indivíduo e gênero humano" (SANTOS; ALMEIDA; ABREU, 2015, p. 2), bem como mencionam o direito negado da população ao acesso e permanência em diferentes setores sociais. Desse modo, tocam em aspectos interseccionais, mas não se atém a eles. Em relação à raça, não é feita nenhuma consideração específica em todo o artigo.

Já o segundo artigo, denominado Extensão Universitária e Identidades Dissidentes: uma experiência concreta de reposicionamento crítico, é de autoria de Júlia Silva Vidal e versa sobre o Programa de Pesquisa e Extensão 'Polos de Cidadania' da Faculdade de Direito e Ciências do Estado da Universidade Federal de Minas Gerais (UFMG). Segundo a autora, o projeto realiza diversas ações, desde assessoria jurídica até atividades e oficinas culturais. Entretanto, apenas depois de 20 anos de existência o projeto passou a incluir ações que envolvem desigualdades de gênero. Vale ressaltar que o artigo demarca que tal fato ocorreu em função da demanda de uma transexual, ao procurar o grupo para tratar de questões sobre sua retificação de documentos. No texto, a palavra lésbica aparece uma vez ao falar da ordem jurídica que "deixa os aspectos de gênero e sexualidade à margem de suas preocupações tradicionais, forjando cada vez mais um hiato entre a reivindicação e a conquista de direitos fundamentais para lésbicas, gays, bissexuais, travestis e transexuais" (VIDAL, 2015, p. 2). A questão de raça e identidade é mencionada através de uma citação que explicita a necessidade de não tratar direitos humanos de modo generalista, visto que desta forma se tende a considerar como de todas as pessoas os valores de homens brancos e heterossexuais. No restante do artigo, encontramos a menção de um projeto desenvolvido pelo grupo, que objetiva "analisar os desdobramentos oriundos do cruzamento de marcadores da diferença existentes na inteligibilidade do gênero no interior de uma favela" (VIDAL, 2015, p. 4).

O terceiro trabalho, dos quatro que representam as visibilidades transparentes, se intitula Pedagogias alternativas: des-construções de gênero e sexualidade no currículo universitário via estética fílmicas, de Marcelo Henrique de Miranda e Jose Wilson Fernandes Neto. Trata-se de texto publicado no Desfazendo Gênero II, em 2015, no qual se narra um projeto cujos objetivos se voltam para, através de processos educativos alternativos, "contribuir nas desconstruções de estereótipos, preconceitos, discriminações, homofobia [...], como também na desestabilização da inteligibilidade heteronormativa" (MIRANDA; NETO, 2015, p. 2). Assim, os autores apresentam o projeto em que são exibidos e debatidos filmes, com o objetivo de dialogar sobre gênero. São apresentados seis filmes que foram trabalhados: Tudo Sobre 
Minha Mãe, XXY, A Pele que Habito, Plata Quemada, O Segredo de Brokeback Mountain e $20 \mathrm{~cm}$ - Quanto mede sua felicidade? Especialmente as reflexões deste último filme são discutidas no artigo, em que uma protagonista transexual vive conflitos sobre suas paixões e mudanças corporais. A discussão do artigo gira em torno do objetivo de desestabilizar a ideia de norma, reiterada pelos autores em vários momentos:

\begin{abstract}
Nesse sentido, as diferenças - não são mais compreendidas ou aprendidas nos cotidianos escolares como desigualdades sociais - adquirem uma dimensão política possibilitando um aprendizado em contextos efetivamente democráticos e no aprendizado do direito à diferença e com a diferença (MIRANDA; NETO, 2015, p. 2).
\end{abstract}

Em resumo, o artigo apresenta o projeto, se debruça sobre a explicação do filme $20 \mathrm{~cm}$ - Quanto mede a sua felicidade? e faz considerações sobre o que concebe como a necessidade de valorização das diferenças. Apesar disto, ao longo do artigo, encontramos apenas a palavra lesbofobia, em dois momentos e na mesma construção de frase, sendo elas: ao mencionar que as temáticas do projeto "constituem assuntos que combate[m] a homofobia, lesbofobia e ou transfobia na materialização de uma pedagogia contrahegemônica na formação docente" (MIRANDA; NETO, 2015, p. 1), e, ao falar da necessidade "do fortalecimento do combate a homofobias, lesbofobias e transfobias" (MIRANDA; NETO, 2015, p. 4). Ou seja, neste trabalho há, ao nosso ver, o entendimento da população LGBT como heterogênea ao especificar lesbofobia e transfobia. Isto pode contribuir para um entendimento de que existem diferenças entre os sujeitos que compõe a sigla, mas sem aprofundar quais seriam as especificidades dos diferentes grupos. Não encontramos considerações sobre a hierarquização entre os diferentes grupos LGBT ou, ainda, sobre os variados sujeitos no interior dessa população. Seguramente, é importante o protagonismo dado a pessoas trans na escolha destes filmes. Ao lado dessa constatação, nos parece necessário ressaltar que dos 6 filmes referenciados no artigo, nenhum deles apresenta protagonistas mulheres lésbicas ou bissexuais, e tão pouco pessoas que não sejam brancas. As escolhas conduzem aos silenciamentos e à falta de representatividade, o que é ainda mais preocupante em textos que refletem práticas que se baseiam em trabalho com identidades, diferenças e diversidade.

Cumpre ainda ressaltar que no trabalho em tela não há nenhuma menção a raça, classe, idade ou geração, nem a qualquer outro aspecto que constitua a problematização de quais as formas que se dão as construções das diferenças hierarquizadas e dos binarismos, mesmo o de gênero. Marcamos, mais uma vez, a ausência da discussão sobre racismo e misoginia, que na visão das autoras do presente artigo são intrinsicamente relacionados com a 
produção de normatizações e que precisam ser retomadas nestas discussões, para fazê-las avançar.

O quarto trabalho que corresponde ao tipo visibilidade transparente tem como título O PIBID como espaço formativo de desarranjos, reinvenções e pluralizações dos gêneros e das sexualidades, escrito pelo pesquisador Marcos de Souza. O texto foi publicado em 2015, na ANPEd 37. Neste artigo, a lesbianidade é apresentada pelo autor e debatida. Em razão dessa aparição mais numerosa de palavras relacionadas às lésbicas e situações sobre a sexualidade de mulheres, nos deteremos mais detalhadamente neste trabalho. Além disto, este artigo é mais extenso que os outros, o que também justifica maior aprofundamento sobre ele. Trata-se de pesquisa onde são analisadas conversas sobre experiências escolares com educadoras do PIBID, em que se discute a formação de professores/as, o denominado trabalho com gênero e sexualidade dentro da escola, bem como suas tensões com a direção e a família e, além disto, situações de sala de aula em que as construções de gênero e acerca da sexualidade se tornam emergentes. Como material de análise, o autor selecionou trechos de entrevistas com cinco situações, as quais comentaremos a seguir.

$\mathrm{Na}$ primeira situação, ocorre uma conversa com pais de uma escola sobre uma proposta de trabalhar sexualidade com estudantes, em que a professora tranquiliza os pais sobre isto. Nesta situação, o autor destaca a necessidade de autorização da família ao se falar sobre o tema, ao lado da ideia de que a criança não tem sexualidade alguma e, por isso, deve-se evitar falar com ela sobre o assunto para não incentivá-la.

$\mathrm{Na}$ segunda situação, uma menina em um colégio evangélico vai de unhas pintadas para a aula e a coordenação retira o esmalte no intervalo. $O$ autor destaca neste trecho a falta de discussão sobre o que significa uma mulher pintar as unhas, se há um desejo de deixar a menina "pura" e, desta forma, questiona qual produção sobre ser mulher está sendo reforçada nesta escola. Percebemos aqui a discussão do controle do corpo da mulher de modo a resguardá-la para o casamento, com trechos em que 0 autor aborda a misoginia.

$\mathrm{Na}$ terceira situação mencionada, ocorre uma discussão de alunos/as sobre uma telenovela em que surgiu a pergunta se era normal uma mulher beijar outra mulher, na qual a professora, com medo da reação da escola, responde que devem perguntar para seus pais. Nesta discussão, o autor problematiza a homossexualidade vista como algo pecaminoso e aprofunda suas análises na professora e seu receio em conversar sobre sexualidade.

Destacamos especialmente na terceira situação que a professora não disse que $o$ beijo entre duas mulheres seria algo anormal e, embora tenha confiado às famílias o diálogo surgido na escola, não reforçou como algo 
negativo. O lugar do silêncio e a negação em dialogar a respeito explicita, contudo, que esse conteúdo não tem lugar ali, na escola, como devem ter as assertivas sobre português ou matemática.

$\mathrm{Na}$ quarta situação, é relatado que um menino de 4 anos solicitava para as colegas que abaixassem a calcinha para ele. Ademais, nesta situação, há o relato da fala do avô do menino que afirma achar melhor elas abaixarem para ele do que serem lésbicas. Com quase duas páginas, a análise do autor sobre esta situação se centra na discussão da masculinidade do garoto em questão, sem mencionar o grande problema representado pelo avó, adulto referente que socializa a criança na direção de naturalizar o estupro e a violência contra todas as mulheres, como se isso as corrigisse no caso de estarem "rumando" para a lesbianidade. No texto, é feita uma menção sobre como esta atitude atinge as meninas:

A construção de um modelo de masculinidade a ser seguido passa também pela ideia dos garotos serem estimulados, desde cedo, a seduzir as meninas, estimulando que elas exibam o seu corpo para eles. O corpo da mulher ainda é visto como fonte de desejo e prazer para o homem heterossexual, a fim de satisfazê-lo. A cena nos impulsiona a problematizar as inúmeras formas que têm sido utilizadas para a produção dos garotos nas normas esperadas para a masculinidade [...] [grifo nosso] (SOUZA, 2015, p. 10).

Desta forma, o autor menciona a imposição da heterossexualidade de forma compulsória às mulheres, entretanto, não desenvolve este ponto, colocando o olhar para a construção da masculinidade, ponto que ele desenvolve nos parágrafos seguintes.

Na última situação mencionada, uma professora relata que, em uma escola, haviam dois irmãos que não se encaixavam em estereótipos de gênero: o menino, por usar um collant rosa, e a menina, por jogar futebol. É mencionado pela professora que a mãe das crianças via com naturalidade as atitudes dos filhos e, por esta razão, segundo a professora, a situação não gerou maiores debates na escola. Nesta situação, o autor analisa a quebra do modelo dicotômico de gênero com o menino e a menina, mas se atém, em diversos parágrafos, em discutir apenas a construção da masculinidade, como se gênero não fosse uma categoria relacional, como nos lembra Joan Scott, no emblemático texto Gênero: uma categoria útil de análise histórica (1990).

A situação do menino é discutida, enquanto a da menina é apenas citada. Tão pouco a construção de gênero da menina é aprofundada em outros parágrafos, como ocorreu com a masculinidade. Trazemos, como exemplo para representar como este movimento acontece, o parágrafo a seguir: 
A educadora nos traz o caso, ocorrido no início de sua carreira, de um garoto que gostava de usar um colã rosa e dançar para as professoras durante as atividades livres. Conforme a educadora: "Ele adorava muito o Chacrinha, adorava dançar aí a mãe mandava na mochila dele um colã rosa". Essa atitude do garoto transgride o que a norma coloca como esperado para os garotos: um homem jamais pode usar um colã, sobretudo, rosa. Outras formas de subversão de meninos já ocorreram em outros contextos, contudo nesse acontecimento destaca-se como a mãe do garoto não via isso como "anormalidade" e não o repreendia, ao contrário, colocava o colã rosa em sua bolsa e gostava que ele dançasse para as educadoras. A outra situação apresentada nesse caso foi sobre a irmã do garoto que tinha uma voz mais grave e gostava de jogar futebol com os meninos e isso também não era censurado pela mãe (SOUZA, 2015, p. 12).

Como pode ser visto, análises que focalizam as relações de gênero com focos se voltando constantemente para os meninos se repetem em outros trechos do texto, dando menos visibilidade às situações que se passam com as meninas:

Esse episódio também nos mobiliza pensar que as famílias apresentam compreensões sobre gênero e sexualidade diversificados e não uniformes como, usualmente, achamos e até ouvimos de algumas escolas. A mãe das crianças ensinou a escola a perceber que o fato de o garoto ter atitudes que não estariam previstas nas normatizações de gênero e de sexualidade não a faz rejeitá-lo ou corrigi-lo, pelo contrário, o desejo da criança foi reconhecido e valorizado pela família (SOUZA, 2015, p. 13).

Nos parágrafos seguintes, é trazida mais uma discussão sobre a quebra de padrões de masculinidade por meninos. A menina, que jogava futebol, poderia estar mencionada nesse parágrafo (como em outros) como uma criança que também transgride a normatização de gênero e é reconhecida e valorizada pela família. Contudo, ela não é mencionada e o foco segue sendo os meninos.

Ao final do texto, o autor afirma que as professoras destacam as discussões sobre a construção de uma masculinidade hegemônica em suas falas. Entretanto, ao menos analisando as falas que nos foram apresentadas, este destaque não nos parece óbvio, visto que as professoras apresentam situações e se mostram inquietas também com a construção da feminilidade e da sexualidade de meninas. Assim, nos parece precoce assegurar que são as professoras que fazem esse destaque, talvez realizado sobretudo pelo pesquisador.

Assim sendo, o artigo O PIBID como espaço formativo de desarranjos, reinvenções e pluralizações dos gêneros e das sexualidades se destaca em

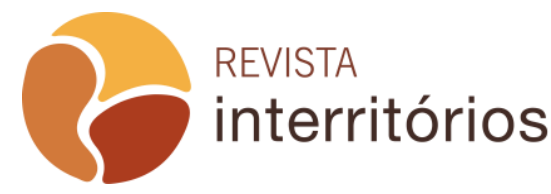


nosso corpus por incluir lesbianidades em seu texto e, ademais, critica a heterossexualidade imposta e a misoginia como questões que devem ser enfrentadas na construção de gênero debatidas na escola. Contudo, essa inclusão aparece de modo superficial e praticamente tímida ao se referir às meninas e mulheres, enquanto a construção da masculinidade é ressaltada e explorada durante todo o artigo. Sobre outras intersecções, como raça e classe, mais uma vez não encontramos consideração no trabalho, como nos demais.

\section{Visibilidade Palpável}

O único texto correspondente ao que denominamos como visibilidade palpável é de autoria da pesquisadora Tatiana Lionço, se intitula Rodas de conversa e denúncia sobre violências em universidades: uma aposta no Teatro do Oprimido, e foi publicado no Desfazendo Gênero III, 2017.

Ao fazer referência a esse texto utilizamos a metáfora de uma visibilidade palpável pois tal adjetivo se refere ao que pode ser tocado, em uma imagem de concretude ao que se encosta. Palpável foi termo escolhido para definir a maneira como a lesbianidade aparece no texto em tela pois também é uma palavra que se profere para falar daquilo que se pode enxergar, que pode ser percebido e que se faz visível a olho nu. Desta maneira, as lésbicas no trabalho têm uma visibilidade palpável no sentido em que a visão que temos delas não é abstrata. No texto de Lionço, as lésbicas não escapam aos nossos olhos como um relâmpago ou uma silhueta transparente, sem conteúdo definido. Assim, abaixo, explicitamos o quão palpável é a visibilidade do artigo selecionado.

Lionço inicia o artigo apresentando o projeto de extensão denominado Escuta Diversa: rede de proteção para a comunidade $L G B T$ da UnB; em seguida, a pesquisadora traz uma série de relatos oriundos de rodas de conversa e, ao final, apresenta as experiências de duas ações artísticas. Os relatos apresentados são todos breves, de poucas linhas, demonstrando as inúmeras situações de violências cometidas contra LGBTs, como ataques pessoais, assédios e constrangimentos. Nesta parte, ainda que as situações sejam pouco detalhadas, o suicídio de uma aluna lésbica é lembrado como gerador de debates entre os estudantes, sobre a necessidade de espaços protegidos na universidade. Também são incluídas duas situações envolvendo mulheres bissexuais, uma que teve seu tarot queimado no campus e outra que passou por um grupo de evangélicos, que levantaram a mão para ela e oraram para sua salvação. Além disto, a autora, de modo geral, coloca a população LGBT como formada por sujeitos diversos, fazendo pequenas - mas existentes - considerações sobre suas especificidades, como o trecho abaixo:

Outra questão que se repete no relato de estudantes, sobretudo mulheres lésbicas e bissexuais, é o da objetificação decorrente 
da visibilidade de suas orientações sexuais, passando a ser reduzidas a estas, muitas vezes com o acompanhamento de assédios sexuais e também exclusão de grupos de contextos acadêmicos e de sociabilidade (LIONÇO, 2017, p. 2525).

Desta forma, apesar das menções a lésbicas serem curtas - como as menções a outros sujeitos - elas não são colocadas no mesmo lugar da homossexualidade masculina, não são ignoradas e não são preteridas em razão de outras discussões. As relações com classe social, raça e religião são feitas em vários momentos, embora pouco aprofundadas, como, por exemplo, ao pontuar que o racismo age concomitantemente à homofobia no ataque a uma estudante bissexual negra e, também, ao mencionar que no campus "são recorrentes relatos de racismo, LGBTfobia e intolerância religiosa" (LIONÇO, 2017, p. 2524). Ademais, a autora marca a existência de espaços de resistência negra em dois campus: na Faculdade de Ceilândia, a existência de dois coletivos, um feminista (Aflora) e um de luta contra o racismo (NegroSUS); e no campus Darcy Ribeiro, a existência do "Centro de Convivência Negra, uma Maloca (espaço indígena), o Quilombo e diversos coletivos estudantis, tais como Corpolítica, (R)Existir e Afrobixas" (LIONÇO, 2017, p. 2526).

Enfim, depois de muito buscar, encontramos uma análise que engloba a abordagem interseccional no trabalho de Tatiana Lionço, posto que ela considera classe, raça e gênero como relacionadas na produção de violências, sem colocar as lésbicas em segundo plano, como nos demais textos analisados. Apesar desse mérito do artigo, importa destacar que, no texto, o que se torna palpável são as violências que as mulheres sofrem pelo fato de serem lésbicas. Em que se pese os limites de um trabalho a ser apresentado em evento, não foi enfatizada a visibilidade da vivência do desejo, da afetividade e do fortalecimento da lesbianidade, que também existem e fazem parte da sociabilidade e vida das lésbicas. Caso contrário, por que, afinal, as lésbicas suportariam tantas violências como as sabidas e narradas pela autora?

\section{Considerações Finais}

Neste trabalho, a partir de um corpus de 145 artigos sobre ensino superior, gênero e feminismos, selecionamos a categoria Ações na Universidade para análise, contendo16 trabalhos. Dentro deste universo, encontramos 8 trabalhos em que a palavra lésbica, sinônimos e/ou derivadas desta palavra apareciam. Esses artigos foram a base para análise no presente texto, no qual ressaltamos a falta de considerações sobre lésbicas na maioria das produções.

Seguramente, não estamos tentando afirmar que todos os trabalhos devem ser sobre lésbicas ou tê-las em sua centralidade. O que nos propomos a problematizar é a baixa frequência de trabalhos sobre este grupo, no campo

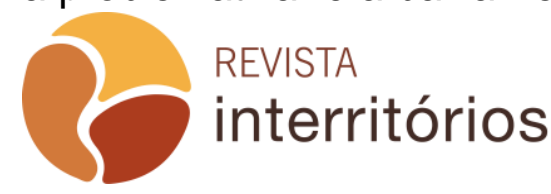


teórico de eventos acadêmicos sobre ensino superior, principalmente quando se percebe a ausência de lésbicas em trabalhos que versam sobre desigualdades e normatizações de gênero. Ainda, quando encontrada a palavra lésbica, nossas analises indicam que isto não significa que este grupo foi considerado na discussão sendo, frequentemente, invisibilizadas e, provavelmente, não tendo sido ouvidas.

Em relação a como são mencionadas as lésbicas nestes trabalhos, nos utilizamos de metáforas para separar os artigos. Na visibilidade relâmpago, apresentamos três trabalhos em que lésbicas aparecem rapidamente: a) 0 trabalho de María del Carmen Acuña-Rodríguez, que usa lésbica na referência a uma data que contém a luta contra lesbofobia, homofobia e transfobia, no qual raça e classe são mencionados brevemente uma vez e sem relação com questões de gênero; b) $\mathrm{O}$ artigo de Eloisa Slongo e Emylli Nascimento, ao citar o nome de um coletivo lésbico, no qual nenhuma relação entre raça, classe e gênero são feitas e; c) no artigo de autoria de Sergio Luiz da Silva, em que a palavra lésbica aparece na descrição de que uma das bolsistas do projeto de extensão era lésbica, no qual encontramos relações com outros aspectos, principalmente de raça, conforme discutido na seção anterior. Nestes artigos, que denominamos visibilidade relâmpago, há a presença de palavras que marcam a existência lésbica, entretanto, isto ocorre quase casualmente, sem maiores considerações.

Nos quatro trabalhos que denominamos a visibilidade lésbica como transparente, a palavra lésbica, sinônimos e/ou derivadas são mencionadas de modo a fazer distinção entre os diferentes sujeitos da população LGBT, ou seja, marcando que há lésbicas, homens gays, bissexuais e pessoas trans, embora sem demonstrar especificidades entre esses grupos. Certamente, destacamos a importância dos quatro trabalhos que discriminam os diferentes sujeitos LGBTs, visto que reafirmam que as desigualdades sociais a que estão submetidos não são as mesmas e não acontecem da mesma forma. Destes, dois dos artigos focalizam questões de direitos humanos específicas para pessoas trans, o que parece de certo modo justificar o não aprofundamento da discussão sobre lésbicas, são eles: a) o de autoria de Márcia Santos, Guilherme Almeida e Andressa Abreu, em que classe social é citada brevemente como um aspecto a ser considerado, embora não desenvolvido no texto, e sem a presença do debate sobre raça; e b) outro trabalho de Júlia Silva Vidal, no qual a única menção a raça é feita, através de uma citação em que raça deve ser considerada ao tratar de direitos humanos, também com gênero.

Nos outros dois trabalhos enquadrados em visibilidade transparente, as lésbicas aparecem e, em seguida, são excluídas da discussão: a) no trabalho de Marcelo Henrique de Miranda e Jose Wilson Fernandes Neto, em que a desconstrução de padrões binários de gênero se limita à discussão sobre homossexualidade masculina e transexualidade feminina, no qual não há 
nenhuma discussão sobre as relações entre gênero, raça e classe; e b) o trabalho de Marcos de Souza, que se sobrepõe dentro deste universo, por fazer referência mais de uma vez a lésbicas e questões de construção de gênero com meninas. Entretanto, marcamos, mais uma vez, que repetidamente o autor parece querer evitar a discussão sobre lesbianidades, deixando de lado as existências lésbicas, além de não haver relações entre raça, classe e gênero.

No último artigo, de Tatiana Lionço, único representante do que nomeamos visibilidade palpável, há considerações sobre existência lésbica, sem mantê-las afastadas da discussão, mesmo considerando que o artigo não tenha como foco central lesbianidades, e sim as violências sofridas pela população LGBT. Assim, observamos que a autora visibiliza os relatos e histórias que envolvem lésbicas, incluindo-as como parte da população LGBT, sem desconsiderar suas particularidades. Além disto, o trabalho também insere classe e raça como articulados a gênero em suas discussões.

Desta forma, o artigo que ora concluímos pretende ressaltar que, na maioria das produções analisadas, os discursos sobre LGBTs e homossexualidades são esvaziados da presença de lésbicas, assim como estas parecem não estar incluídas nas escolhas de materiais utilizados nos projetos ou como sujeitos da coleta de dados. Ademais, sublinhamos, repetida e propositadamente, a ausência nos trabalhos de relações entre raça, classe e gênero, bem como eventuais aspectos identitários e de condição social que podem se mostrar relevantes historicamente para cada pesquisa. Os únicos trabalhos em que foram encontradas estas relações de modo não superficial foram o trabalho de Sergio Luiz da Silva e de Tatiana Lionço, que em suas análises apresentam discussões de raça e classe como aspectos que não são deslocados de gênero.

Pelas análises aqui tecidas, indicamos que os demais artigos que são foco desta análise, ao não representarem lésbicas e não trazerem abordagens interseccionais, deixam margem para uma visão homogênea da população LGBT, que acaba por priorizar como o todo homens, brancos, cis e de classe dominante. O corpus composto por dez categorias segue em análises que serão divulgadas paulatinamente em novas publicações de nossa autoria.

Finalmente, destacamos que compreendemos a existência de uma lacuna no campo acadêmico em relação a presença de lésbicas, mesmo quando as produções versam sobre a população LGBT. E compreendemos que uma lacuna ainda restará, embora de outro modo, nos escritos que tematizem apenas a lesbofobia, ao considerarem as lésbicas. Dar visibilidade às lésbicas também precisa comportar as vivências dos desejos, dos afetos, dos múltiplos e potentes fortalecimentos das lesbianidades. A visibilidade pela lesbofobia importa pois é necessária ao combate das forças que insistem em nos exterminar. E, ao lado disso, importa que também sejam palpáveis as 
visibilidades que dão conta da sociabilidade pulsante e da vida potente das lésbicas. Caso contrário - e repetimos aqui pergunta feita anteriormente - por que, afinal, as lésbicas suportariam tantas violências como as sabidas e narradas em parte das produções? Sabemos pelo menos parte da resposta, afinal nem todas as boas perguntas tem explicações rápidas, ainda mais quando essas respostas são ainda melhores que a pergunta. Mas deixamos esse diálogo para uma próxima ocasião, que esperamos ocorra em breve e de modo favorável.

\section{REFERÊNCIAS}

ACUÑA-RODRÍGUEZ, María del Carmen. Habitar (em) a burbuja universitária: a universidad de costa rica como espaço de proteção para sua população LGBTI. In: Desfazendo Gênero, III, Campina Grande, 10 - 13 out. 2017. Anais do III Desfazendo Gênero. Campina Grande: UFPB, 2017. p. 1385-1391.

AUAD, Daniela. Relações de gênero nas práticas escolares: da escola mista ao ideal de co-educação. 2004. 232 p. Tese (Doutorado em Educação: Sociologia da Educação) - Faculdade de Educação, Universidade de São Paulo, São Paulo.

AUAD, Daniela; CORDEIRO, Ana Luisa Alves. A interseccionalidade nas políticas de ação afirmativa como medida de democratização da educação superior. Eccos, $n$. 45, p. 191-207, 2018. Disponível em:

https://periodicos.uninove.br/index.php?journal=eccos\&page=article\&op=view\&path\% 5B\%5D=7959. Acesso em: 12 Set 2019.

AUAD, Daniela; LAHNI, Cláudia Regina. Cidadania Democrática e homossexualidades: comunicação no combate à violência contra as mulheres lésbicas. Emblemas - Revista do Departamento de História e Ciências Sociais. UFG. Catalão, Goiás. v. 10, n. 2, p. 147-166, 2013. Disponível em: https://revistas.ufg.br/emblemas/article/view/29240/16264. Acesso em: 23 Set 2019.

BENEVIDES, Bruna G.; NOGUEIRA, Sayonara N. B. Dossiê Assassinatos e violências contra travestis e transexuais no Brasil em 2018. Brasil: Associação Nacional de Travestis e Transexuais do Brasil, 2018. Disponível em: https://antrabrasil.org/relatorios Acesso em 14 set 2019.

CLARKE, Cheryl. El lesbianismo: Un Acto de Resistencia. In: MORAGA, Cherríe; CASTILLO, Ana. Esta Puente, mi espalda: Voces de las tercermundistas en los Estados Unidos. ISM Press: São Francisco - USA, 1988, p. 98-107.

GGB - GRUPO, GAY DA BAHIA. Mortes violentas de LGBT+ no Brasil: Relatório 2018. Bahia: Grupo Gay da Bahia, 2019. Disponível em: https://grupogaydabahia.com.br/. Acesso em: 12 set 2019.

LIONÇO, Tatiana. Rodas de conversa e denúncia sobre violências em universidades: uma aposta no teatro do oprimido. In: Desfazendo Gênero, III, Campina Grande, 10 13 out. 2017. Anais do III Desfazendo Gênero. Campina Grande: UFPB, 2017. p. 2523-2526. 
LORDE, Audre. Não há Hierarquias de Opressão. In: Textos escolhidos de Audre Lorde. Difusão Herética Lesbofeminista, fanzine, p. 5-6, s/d.

MIRANDA, Marcelo Henrique; FERNANDES NETO, Jose Wilson. Pedagogias alternativas: des-construções de gênero e sexualidade no currículo universitário via estética fílmica. In: Desfazendo Gênero, II, Salvador, 04 - 07 set. 2015. Anais do II Desfazendo Gênero. Salvador: UFBA, 2015. Disponível em: http://www.desfazendogenero.ufba.br/. Acesso em: 12 set 2019.

PERES, Milena Cristina Carneiro; SOARES, Suane Felippe; DIAS, Maria Clara. Dossiê sobre lesbocídio no Brasil: de 2014 - 2017. Rio de Janeiro, Livros llimitados, 2018.

PROJETO DE PESQUISA LESBOCÍDIO. Lesbocídio: As histórias que ninguém conta, 2018. Lesbocídios Nacionais. Disponível em:

https://www.lesbocidio.com/lesbocidios-nacionais. Acesso em: 26 Jul 2019.

$\mathrm{RICH}$, Adrienne. Heterossexualidade compulsória e a existência lésbica. Trad. Carlos Guilherme do Valle. Revista Bagoas, v.4, n. 5, p.17-44, 2010. Disponível em: https://periodicos.ufrn.br/bagoas/article/view/2309. Acesso em: 12 Set 2019.

ROSEMBERG, Fúlvia. Educação formal, mulher e gênero no Brasil contemporâneo. Revista Estudos Feministas, v. 9, n. 2, p. 515-540, 2001. Disponível em: http://www.scielo.br/scielo.php?pid=S0104026X2001000200011\&script=sci_abstract\&tlng=pt. Acesso em: 12 Set 2019.

SANTOS, Márcia; ALMEIDA, Guilherme; ABREU, Andressa. Espaços potentes: a extensão universitária como possibilidade de fortalecimento da ação profissional no campo interventivo. In: Desfazendo Gênero, II, Salvador, 04 - 07 set. 2015. Anais do II Desfazendo Gênero. Salvador: UFBA, 2015. Disponível em: http://www.desfazendogenero.ufba.br/. Acesso em: 12 set 2019.

SCOTT, Joan W. Gênero: uma categoria útil de análise histórica. Educação e Realidade, vol. 16, n. 2, Porto Alegre, jul./dez. 1990.

SILVA, Sergio Luiz Baptista. Uso e elaboração de material didático no PIBID-Francês - UFRJ: abordando raça, gênero e sexualidades In: Desfazendo Gênero, III, Campina Grande, 10 - 13 out. 2017. Anais do III Desfazendo Gênero. Campina Grande: UFPB, 2017. p. 2848-2852.

SLONGO, Eloisa; NASCIMENTO, Emylli Tavares. Assessoria jurídica universitária popular: o relatório de assassinatos LGBT e os crimes de ódio na paraíba. In: Desfazendo Gênero, II, Salvador, 04 - 07 set. 2015. Anais do II Desfazendo Gênero. Salvador: UFBA, 2015. Disponível em:

http://www.desfazendogenero.ufba.br/. Acesso em: 12 set 2019.

SOUZA, Marcos. O PIBID como espaço formativo de desarranjos, reinvenções e pluralizações dos gêneros e das sexualidades. In: Reunião Anual da Associação Nacional de Pós-graduação e Pesquisa em Educação - ANPEd, 37, Florianópolis, 04 - 08 out. 2015. Anais da 37a Reunião Anual da Associação Nacional de Pósgraduação e Pesquisa em Educação - ANPEd. Florianópolis: UFSC, 2015. Disponível em: http://37reuniao.ANPEd.org.br/trabalhos/. Acesso em: 12 set 2019. 
VIDAL, Júlia Silva. Extensão Universitária e Identidades Dissidentes: uma experiência concreta de reposicionamento crítico. In: Desfazendo Gênero, II, Salvador, $04-07$ set. 2015. Anais do II Desfazendo Gênero. Salvador: UFBA, 2015. Disponível em: http://www.desfazendogenero.ufba.br/. Acesso em: 12 set 2019. 